\title{
Comparative Studies on Optical and Electronic Behavior of Lanthanide-based Coordination Polymers: Synthesis, Structure, Absorption-Emission and Magnetic Properties
}

\author{
PRABU MANI ${ }^{\mathrm{a}}, \mathrm{K}^{\mathrm{M}}$ RANJITH ${ }^{\mathrm{b}}$, SUKHENDU MANDAL $^{\mathrm{a}}$ and AVIJIT KUMAR PAUL ${ }^{\mathrm{c}, *}$ (1) \\ ${ }^{a}$ School of Chemistry, Indian Institute of Science Education and Research, Thiruvananthapuram, 695016 , \\ Kerala, India \\ ${ }^{\mathrm{b}}$ School of Physics, Indian Institute of Science Education and Research, Thiruvananthapuram, 695 016, Kerala, \\ India \\ ${ }^{c}$ Department of Chemistry, National Institute of Technology, Kurukshetra, 136 119, Haryana, India \\ E-mail: apaul@nitkkr.ac.in
}

MS received 20 November 2017; revised 12 April 2018; accepted 18 April 2018; published online 29 May 2018

\begin{abstract}
A series of lanthanide(III) based coordination polymers have been synthesized using chelidamic acid (CA) as a ligand, [ $\left.\mathrm{Ln}\left(\mathrm{C}_{7} \mathrm{H}_{2} \mathrm{NO}_{5}\right)\left(\mathrm{H}_{2} \mathrm{O}\right)_{3}\right] \cdot \mathrm{H}_{2} \mathrm{O}(\mathrm{Ln}=\mathrm{Eu}, \mathrm{Gd}, \mathrm{Tb}$, and Dy). All the compounds were prepared by solvothermal technique using $\mathrm{H}_{2} \mathrm{O}$-DMF as solvents (4:1, volume ratio). Compounds were characterized through various instrumental techniques such as single-crystal X-ray diffraction, powder X-ray diffraction, thermogravimetric analysis, IR spectroscopy, etc. In all the cases lanthanide ion adopts distorted dodecahedron geometry. And these dodecahedrons are connected through chelidamic acid ligand to form the two-dimensional structure. These layers are H-bonded to form the three-dimensional supramolecular structure. The optical band gap energy measurements exhibit that the variation of the band gap energy is independent of the $f$-electrons. This is due to the weak bonding connectivity between the metal ion and ligands, which could not perturb the density of states significantly. The variable-temperature magnetic measurements exhibit the paramagnetic behavior of all the compounds though the effective magnetic moments rise with increasing number of $f$-electrons. The present study illustrates the usefulness of the lanthanides for the structure building as well as the role of $f$-electrons for opto-electronic behaviors.
\end{abstract}

Keywords. Coordination polymers; lanthanides; crystal structure; band-gap variation; magnetization.

\section{Introduction}

Due to higher coordination number and flexible geometries, lanthanide ions create fascinating structures which have potential applications in material science. ${ }^{1-5}$ Lanthanide coordination polymers (LnCPs) exhibit high luminescence efficiency, narrow bandwidth, and long luminescence lifetime. ${ }^{6}$ Lanthanide metal itself acts as both photoluminescent and magnetic center that make these materials interesting over others. With these advantages, properties related to pore size and surface area, make these ideal materials for developing new multifunctional materials. ${ }^{7-15}$ In comparison with transition metals, lanthanide ions have more flexible and higher coordination numbers varying from 6 to 12. This

\footnotetext{
*For correspondence
}

might lead to more diverse architectures and topologies. ${ }^{16-22}$ The flexibility of the coordination geometry of lanthanides usually results in cluster-based secondary building units (SBUs), which is responsible for thermal robustness of these structures. ${ }^{23-25}$ Lanthanide ions form stable architectures with carboxylate ligand due to high affinity of lanthanides for oxygen. The differences in emission, magnetic and optical properties of lanthanide ions provide a platform to precisely tune these properties. ${ }^{26}$

However, designing a practical method to prepare controlled geometries of LnCPs still remains challenging. ${ }^{27}$ In addition, lanthanide contraction may also affect the coordination number resulting in different crystal structures. ${ }^{28-30}$ Lanthanum metal ion has tendency to coordinate with solvent molecules when reacted with small rigid ligand. It was shown that, choice of

Electronic supplementary material: The online version of this article (https://doi.org/10.1007/s12039-018-1464-x) contains supplementary material, which is available to authorized users. 
organic linkers and effective synthetic strategy produce lanthanide frameworks with intense and long-lived fluorescent emission. Especially, ligands containing both $\mathrm{N}$ - and $\mathrm{O}$ donors can exhibit great adaptability while coordinated to metal center. ${ }^{31-36}$ The coordination ability of the 4-hydroxy derivative of dipicolinic acid, that is, 4-hydroxypyridine-2,6-dicarboxylic acid (Chelidamic acid, CA), will be ideal to explore the structural diversity of LnCPs. ${ }^{37-41}$

In this work, we report synthesis, structure, optical band gap energy and magnetism of a series of chelidamic acid based lanthanide coordination polymers. Among these, compound $\mathbf{1}$ is completely new and other three compounds (2-4) are synthesized in similar conditions to compare their properties though they are reported in the literature. ${ }^{22,42,43}$ Single crystal data analysis revealed that lanthanide polyhedral units are connected with CA ligand to form the layered structure. These layers are H-bonded to form the three-dimensional supramolecular structure. We have measured the optical band gap energy and magnetic properties and correlated with the corresponding structures.

\section{Experimental}

\subsection{Materials}

All chemicals were purchased from Sigma-Aldrich and used without further purification. $\mathrm{Eu}\left(\mathrm{NO}_{3}\right)_{3}, \mathrm{H}_{2} \mathrm{O}, \mathrm{Gd}\left(\mathrm{NO}_{3}\right)_{3}$. $6 \mathrm{H}_{2} \mathrm{O}, \mathrm{Tb}\left(\mathrm{NO}_{3}\right)_{3} .5 \mathrm{H}_{2} \mathrm{O}, \mathrm{Dy}\left(\mathrm{NO}_{3}\right)_{3} \cdot \mathrm{H}_{2} \mathrm{O}$, chelidamic acid (CA), N,N' dimethyl formamide (DMF) and milli-Q water were used for the synthesis. The IR spectra were recorded from prepared $\mathrm{KBr}$ pellets, using IR prestige-21 (Shimadzu) spectrometer. The TGA was performed on SDT Q600 (Shimadzu) analyser. Powder X-ray diffraction data (Figure S1 in Supplementary Information) were collected using an X'pert PRO (PANalytics) powder diffractometer equipped with $\mathrm{Cu} \mathrm{K}_{\alpha}$ radiation $(1.5405 \AA$ ).

\subsection{Synthesis}

2.2a Compound 1: $\mathrm{Eu}\left(\mathrm{NO}_{3}\right)_{3} \cdot \mathrm{H}_{2} \mathrm{O}(0.1 \mathrm{mmol})$ was dissolved in $2 \mathrm{~mL}$ DMF. Chelidamic acid (CA) $(0.1 \mathrm{mmol})$ was dissolved in $8 \mathrm{~mL}$ distilled water separately and $\mathrm{pH}$ of the solution was adjusted to 8 by using $1 \mathrm{M} \mathrm{KOH}$ solution. Both metal and ligand solutions were mixed together in a $20 \mathrm{~mL}$ glass vial then the vial was heated at $100{ }^{\circ} \mathrm{C}$ for 3 days. Colourless block-shaped crystals were obtained. Then crystals were washed with DMF and dried in vacuum for further use. Yield: $60 \%$ based on chelidamic acid.

2.2b Compounds 2-4: Except the metal salt, synthetic procedure of compounds 2-4 were same as the synthesis of compound $\mathbf{1}$. The metal salts $\mathrm{Gd}\left(\mathrm{NO}_{3}\right)_{3} \cdot 6 \mathrm{H}_{2} \mathrm{O}$ (or) $\mathrm{Tb}\left(\mathrm{NO}_{3}\right)_{3} .5 \mathrm{H}_{2} \mathrm{O}$ (or) $\mathrm{Dy}\left(\mathrm{NO}_{3}\right)_{3} \cdot \mathrm{H}_{2} \mathrm{O}$ were used instead of
$\mathrm{Eu}\left(\mathrm{NO}_{3}\right)_{3} \cdot \mathrm{H}_{2} \mathrm{O}$. In all the cases, colourless block-shaped crystals were formed. Crystals were washed with DMF and dried in vacuum for further use. Yield: $55 \%(\mathrm{Gd}), 67 \%(\mathrm{~Tb})$, 63\% (Dy) - based on chelidamic acid. IR peaks for compounds 1-4 $\left(\mathrm{KBr}\right.$ pellet) $\vee\left(\mathrm{cm}^{-1}\right)$ : 1711, 1420-1585, 1350 and $3200-3600$.

\subsection{Single crystal X-ray Diffraction}

The single crystal diffraction data were collected on a Bruker AXS Smart Apex CCD diffractometer at $298 \mathrm{~K}$. The X-ray generator was operated at $50 \mathrm{kV}$ and $35 \mathrm{~mA}$ using $\operatorname{Mo~K}_{\alpha}(\lambda=$ $0.7107 \AA$ ) radiation. A total of 606 frames were collected in three different settings of $\varphi\left(0^{\circ}, 90^{\circ}, 180^{\circ}\right)$ keeping detector position $(2 \theta)$ fixed at $-25^{\circ}$.

The data reduction and empirical absorption correction were done using SAINTPLUS ${ }^{44}$ and SADABS program, ${ }^{45}$ respectively. SHELXS2014 package ${ }^{46}$ was used for the structure solution and refinement. All hydrogen atoms were placed in calculated positions during the final step of the refinement process. For the final refinement, the hydrogen atoms were placed in geometrically ideal positions and refined using the riding mode. The last cycles of the refinement included atomic positions, anisotropic thermal parameters for all the non-hydrogen atoms, and isotropic thermal parameters for all the hydrogen atoms. Full-matrix-least-squares structure refinement against $\mathrm{F}^{2}$ was carried out using the WINGX package of programs. ${ }^{47}$ The crystallographic parameters for compounds 1-4 are provided in Table 1. CCDC 1495104 1495107 contain crystallographic information for compounds 1-4, respectively. These data can be obtained free of charge from The Cambridge Crystallographic Data Centre (CCDC) $v i a$ www.ccdc.cam.ac.uk/data_request/cif

\subsection{Optical Band-Gap Measurements}

The optical absorption spectra of all the compounds were collected on a Shimadzu UV/Vis/NIR spectrophotometer. We have ground the samples with $\mathrm{BaSO}_{4}$ (as reference material) and made a thin film on the glass surface. The films were made between two quartz plates with edges sealed by paraffin tape. Kubelka-Munk function was used to calculate the band gap energy from the optical absorption spectra. ${ }^{48-50}$

We have used a two-flux model to determine the absorption coefficient of the sample. For a crystalline solid with a band gap $\left(E_{\mathrm{bg}}\right)$, the frequency $(v)$ dependence of the absorption coefficient $(\kappa)$ can be approximated as,

$\kappa(v)=\frac{B_{T}\left(h v-E_{b g}\right)^{n}}{h v}$

Where, $\mathrm{B}_{\mathrm{T}}$ is a constant derived from the square of the averaged dipolar momentum matrix element and $\mathrm{n}$ is equal to 0.5 and 2 for direct and indirect band gap transitions, respectively. The absorption coefficient $(\kappa)$ can be measured from the reflectance $(\mathrm{R})$ and expressed as $\kappa=(1-\mathrm{R})^{2} /(2 \mathrm{R})$. Using the above equation, the band gap of a material can be obtained by extrapolating to zero with the linear fit to a plot 
Table 1. Crystallographic parameters for compounds 1-4.

\begin{tabular}{|c|c|c|c|c|}
\hline Parameters & 1 & 2 & 3 & 4 \\
\hline Empirical formula & $\mathrm{Eu} \mathrm{C}_{7} \mathrm{~N} \mathrm{O}_{9} \mathrm{H}_{6}$ & $\mathrm{Gd} \mathrm{C}_{7} \mathrm{~N} \mathrm{O}_{9} \mathrm{H}_{10}$ & $\mathrm{~Tb} \mathrm{C}_{7} \mathrm{~N} \mathrm{O}_{9} \mathrm{H}_{10}$ & Dy $\mathrm{C}_{7} \mathrm{~N} \mathrm{O}_{9} \mathrm{H}_{6}$ \\
\hline Formula weight & 400.09 & 409.41 & 411.08 & 410.63 \\
\hline Crystal system & Monoclinic & Monoclinic & Monoclinic & Monoclinic \\
\hline Space group & P 21/n & P 21/n & P 21/n & P 21/n \\
\hline$a(\AA)$ & $10.0143(2)$ & $9.9820(4)$ & $9.9685(3)$ & $9.9341(5)$ \\
\hline$b(\AA)$ & $7.5382(4)$ & $7.5434(4)$ & $7.5261(2)$ & $7.5412(4)$ \\
\hline$c(\AA)$ & $15.5425(2)$ & $15.5034(7)$ & $15.4811(5)$ & $15.4370(7)$ \\
\hline$\alpha\left(^{\circ}\right)$ & 90 & 90 & 90 & 90 \\
\hline$\beta\left(^{\circ}\right)$ & 104.9100 & 105.035 & 105.0700 & 105.176 \\
\hline$\gamma\left({ }^{\circ}\right)$ & 90 & 90 & 90 & 90 \\
\hline$V\left(\AA^{3}\right)$ & $1133.80(5)$ & $1127.42(9)$ & $1121.51(6)$ & $1116.13(10)$ \\
\hline $\mathrm{Z}$ & 4 & 4 & 4 & 4 \\
\hline $\mathrm{D}\left(\mathrm{calc} / \mathrm{gcm}^{-3}\right)$ & 2.344 & 2.412 & 2.435 & 2.444 \\
\hline$\mu\left(\mathrm{mm}^{-1}\right)$ & 5.573 & 5.925 & 6.348 & 6.736 \\
\hline$\theta$ range $\left(^{\circ}\right)$ & 2.782 to 28.269 & 2.794 to 28.434 & 2.725 to 28.342 & 2.205 to 26.372 \\
\hline Total data collected & 10452 & 10564 & 10282 & 9193 \\
\hline Unique data & 2796 & 2810 & 2771 & 2283 \\
\hline Goodness-of-fit & 1.181 & 1.097 & 1.157 & 1.121 \\
\hline Number of parameters & 177 & 198 & 198 & 183 \\
\hline Final $\mathrm{R}$ indexes $[I>2 \sigma(I)]$ & $\begin{array}{c}\mathrm{R}_{1}=0.0260 \\
\mathrm{wR}_{2}= \\
0.0777\end{array}$ & $\begin{array}{c}\mathrm{R}_{1}=0.0154 \\
\mathrm{wR}_{2}= \\
0.0368\end{array}$ & $\begin{array}{l}\mathrm{R}_{1}=0.0147 \\
\mathrm{wR}_{2}= \\
0.0303\end{array}$ & $\begin{array}{c}\mathrm{R}_{1}=0.0364 \\
\mathrm{wR}_{2}= \\
0.0989\end{array}$ \\
\hline
\end{tabular}

$R_{1}=\Sigma|| F_{0}|-| F_{\mathrm{c}}|| / \Sigma\left|F_{0}\right| ; \mathrm{wR}_{2}=\left\{\left[w\left(F_{0}^{2}-F_{\mathrm{c}}^{2}\right)^{2}\right] /\left[w\left(F_{0}^{2}\right)^{2}\right]\right\}^{1 / 2} ; w=1 /\left[\sigma^{2}\left(F_{0}\right)^{2}+(a P)^{2}+b P\right] ; P=\left[\max \left(F_{0}^{2}, 0\right)+\right.$ $\left.2\left(F_{\mathrm{c}}\right)^{2}\right] / 3: \mathrm{a}=0.0442, \mathrm{~b}=2.9865$ for compound $\mathbf{1}, \mathrm{a}=0.0100, \mathrm{~b}=1.7234$ for compound $2, \mathrm{a}=0.0027, \mathrm{~b}=1.7830$ for compound $\mathbf{3}, \mathrm{a}=0.0535, \mathrm{~b}=1.5641$ for compound $\mathbf{4}$, respectively.

of $(\kappa \mathrm{h} v)^{1 / \mathrm{n}} v s . \mathrm{h} v$. The lowest electronic transition between valence and conduction bands is the optical band gap of the material.

\subsection{Magnetic Measurements}

The magnetic properties were measured using a vibrating sample magnetometer (VSM) attachment in a commercial (Quantum Design) physical property measurement system (PPMS). Magnetic susceptibility $\chi$ as a function of temperature (T) was measured at different applied fields and over a large $T$-range ( $2 \mathrm{~K} \leq \mathrm{T} \leq 380 \mathrm{~K}$ ). Magnetization isotherm (magnetization $\mathrm{M} v s$. applied field $\mathrm{H}$ ) was also measured at $T=2.1 \mathrm{~K}$ up to a maximum varying field of $9 \mathrm{~T}$.

\section{Results and Discussion}

\subsection{Structure description}

Compounds 1-4 crystallize in the monoclinic crystal system with space group $P 2_{1} / c$. Asymmetric unit of each compound contains one Ln metal center, one chelidamic acid ligand, three coordinated water molecules and one lattice water molecule. All the compounds are isostructural and possess a two-dimensional architecture. In all the cases Ln ion has eight coordination and adopts distorted dodecahedron geometry. Four oxygen atoms and one nitrogen atom from the chelidamic acid ligand and three coordinated water molecules satisfy the eight coordination (Figure 1a). The Ln - O bond lengths are in the range of 2.293-2.501 $\AA$, Ln - $\mathrm{N}$ bond lengths are in the range of $2.435-2.487 \AA$ (Table 2). In the chelidamic acid one of the carboxylate group bonded with metal in $\mu_{2}: \eta^{1}: \eta^{1}$ mode while another carboxylate group has the $\mu_{1}: \eta^{1}$ mode (Figure $\mathrm{S} 4 \mathrm{a}$ in Supplementary Information). This connectivity between lanthanide metal ion and chelidamic acid gives rise to two-dimensional structure (Figure 1b). Furthermore, the 2D frameworks are further assembled to form a 3D supramolecular network by the hydrogen bonds between water molecules and carboxylate $\mathrm{O}$ atoms or hydroxyl groups (Figure S4b in Supplementary Information). The extensive H-bonding between coordinated water and framework oxygen atoms, coordinated water and lattice water molecules play crucial role for the stability of the structure. Interestingly, coordinated and lattice water molecules H-bonded to form the tetrameric water cluster (Figure S5 in Supplementary Information). Topological analysis using TOPOS software identified that all the four structures have same topological network with uninodal net, 5-c net, which can be presented 
(a)

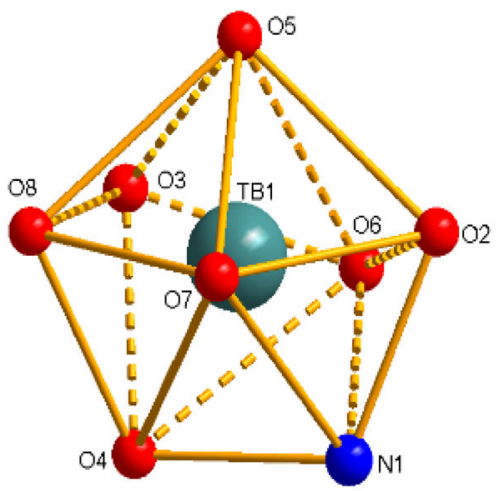

(b)

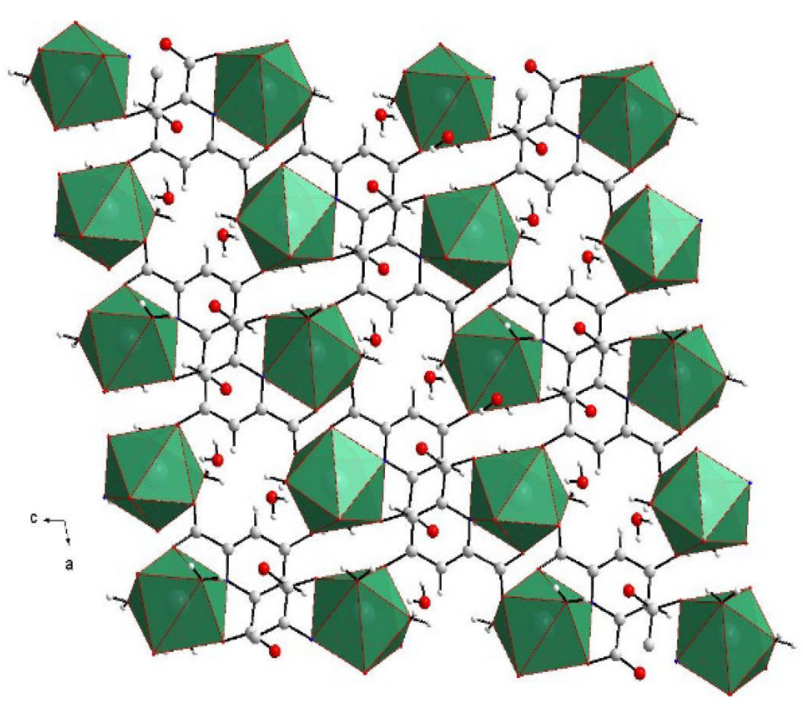

Figure 1. (a) Distorted dodecahedron geometry of $\mathrm{LnO}_{7} \mathrm{~N}$ unit. (b) Two-dimensional layered architecture.

as a Schläfli symbol $\left\{3^{3} \cdot 4^{3} \cdot 5^{4}\right\}(\operatorname{td} 10=294)$ (see Supplementary Information). ${ }^{51}$

\subsection{Band Gap Energy}

The diffuse reflectance spectra of the powder samples of compounds 1-4 as well as Na-salt of the ligand were collected in order to measure the optical band gap energy $\left(E_{b g}\right)$. The optical band gap energy was confirmed as the intersection point between the energy axis and the line extrapolated from the linear portion of the absorption edge in a plot of Kubelka-Munk function vs. energy (Figure S6 in Supplementary Information). The band gap values are given in Table 1. Structural description of compounds 1-4 revealed that the metal nodes are well isolated and connected by an organic linker. The electronic structure calculations on these types of compounds predicted that the HOMO-LUMO gap of the organic ligand determines the band gap of these materials. ${ }^{52-54}$ In this case, the band gap energy varies from $3.70 \mathrm{eV}$ to $3.85 \mathrm{eV}$ for compounds $\mathbf{1}-\mathbf{4}$. The band gap
Table 2. Selected bond distances $(\AA)$ of compounds 1-4.

\begin{tabular}{lccc}
\hline Bond & Distance $(\AA)$ & Bond & Distance $(\AA)$ \\
\hline Compound 1 & & & \\
Eu(1)-O(8) & $2.330(3)$ & $\mathrm{Eu}(1)-\mathrm{N}(1)$ & $2.435(3)$ \\
$\mathrm{Eu}(1)-\mathrm{O}(4)$ & $2.402(4)$ & $\mathrm{Eu}(1)-\mathrm{O}(6)$ & $2.445(3)$ \\
Eu(1)-O(7) & $2.424(3)$ & $\mathrm{Eu}(1)-\mathrm{O}(2)$ & $2.450(3)$ \\
Eu(1)-O(3) & $2.432(4)$ & $\mathrm{Eu}(1)-\mathrm{O}(5)$ & $2.501(3)$ \\
Compound 2 & & & \\
Gd(1)-O(1) & $2.3225(15)$ & $\mathrm{Gd}(1)-\mathrm{O}(3)$ & $2.4254(15)$ \\
$\mathrm{Gd}(1)-\mathrm{O}(5)$ & $2.3829(18)$ & $\mathrm{Gd}(1)-\mathrm{O}(2)$ & $2.4277(18)$ \\
$\mathrm{Gd}(1)-\mathrm{O}(8)$ & $2.3960(18)$ & $\mathrm{Gd}(1)-\mathrm{O}(6)$ & $2.4385(15)$ \\
$\mathrm{Gd}(1)-\mathrm{O}(4)$ & $2.4209(16)$ & $\mathrm{Gd}(1)-\mathrm{N}(1)$ & $2.4870(17)$ \\
Compound 3 & & & \\
Tb(1)-O(5) & $2.306(19)$ & $\mathrm{Tb}(1)-\mathrm{O}(3)$ & $2.413(18)$ \\
$\mathrm{Tb}(1)-\mathrm{O}(6)$ & $2.365(2)$ & $\mathrm{Tb}(1)-\mathrm{O}(8)$ & $2.417(2)$ \\
$\mathrm{Tb}(1)-\mathrm{O}(7)$ & $2.381(2)$ & $\mathrm{Tb}(1)-\mathrm{O}(2)$ & $2.429(17)$ \\
Tb(1)-O(4) & $2.409(19)$ & $\mathrm{Tb}(1)-\mathrm{N}(1)$ & $2.475(2)$ \\
Compound 4 & & & \\
Dy(1)-O(6) & $2.293(3)$ & $\mathrm{Dy}(1)-\mathrm{O}(8)$ & $2.401(3)$ \\
Dy(1)-O(3) & $2.354(3)$ & $\mathrm{Dy}(1)-\mathrm{O}(7)$ & $2.405(3)$ \\
Dy(1)-O(5) & $2.372(3)$ & $\mathrm{Dy}(1)-\mathrm{O}(2)$ & $2.415(3)$ \\
Dy(1)-O(4) & $2.401(3)$ & $\mathrm{Dy}(1)-\mathrm{N}(2)$ & $2.461(3)$ \\
\hline
\end{tabular}

Table 3. Experimentally measured band gap energy for compounds 1-4 and Na-salt of ligand, respectively.

\begin{tabular}{lc}
\hline Compound & Band Gap Energy $(\mathrm{eV})$ \\
\hline Na-salt of ligand & $3.84 \pm 0.02$ \\
Eu-CA (1) & $3.70 \pm 0.03$ \\
Gd-CA (2) & $3.76 \pm 0.02$ \\
Tb-CA (3) & $3.85 \pm 0.01$ \\
Dy-CA (4) & $3.75 \pm 0.01$ \\
\hline
\end{tabular}

energy of the Na-salt of the ligand was $3.84 \mathrm{eV}$. It was shown that the band gap energy decreases from the ligand molecule and the difference is negligible. This proved that the perturbation of the states related to conduction and valence bands are not significant. All the compounds have a similar structure with identical bonding connectivity of the ligand and metal ion. The only difference is the number of f-electrons in the corresponding metal ion, which may have little effect towards the band gap energy (Table 3).

\subsection{Magnetic properties}

The temperature dependent magnetic susceptibilities of compounds 2-4 were measured from $2 \mathrm{~K}$ to $380 \mathrm{~K}$ in an external magnetic field of $1 \mathrm{~T}$. The magnetic measurements were not performed for compound $\mathbf{1}$ as the effective momentum of the Eu-based compound is 
almost zero. In order to extract the magnetic parameters, the inverse magnetic susceptibility $(1 / \chi)$ data in the high- $T$ regime were fitted by the Curie-Weiss $(\mathrm{CW})$ equation:

$$
\chi=\left[\chi_{0}+\mathrm{C} /\left(T-\theta_{C W}\right)\right]
$$

Where, $\chi_{0}$ is the $T$-independent susceptibility which includes core diamagnetic susceptibility $\left(\chi_{\text {core }}\right)$ and Van-Vleck paramagnetic susceptibility $\left(\chi_{\mathrm{VV}}\right)$. In the second term in the $\mathrm{CW}$ eq., Curie constant $C=$ $\left[N_{A} g^{2} \mu_{\mathrm{B}}^{2} / 3 k_{B}\right] S(S+1)$, where $\mathrm{N}_{\mathrm{A}}$ - Avogadro Number, $g$ - Landé g-factor, $\mu_{\mathrm{B}}$ - Bohr magneton, $k_{\mathrm{B}}$ - Boltzmann constant, $S$ - spin quantum number, $T$ - Temperature, and $\theta_{\mathrm{CW}}$ the characteristic Curie-Weiss temperature. The experimental effective moment $\mu_{\text {eff }}$ was calculated from the room temperature $\chi T$ value using the equation, $\mu_{\text {eff }}=2.83 \sqrt{\chi T}$.

For Compound 2, as shown in Figure 2a, $\chi(T)$ increases with a decrease in temperature. Indication of magnetic ordering was not observed in the studied temperature range. $\chi T(T)$ is equal to $7.92 \mathrm{~cm}^{3} \mathrm{~K} \mathrm{~mol}^{-1}$ at $350 \mathrm{~K}$, which is close to the value expected $\left(7.87 \mathrm{~cm}^{3}\right.$ $\left.\mathrm{K} \mathrm{mol}^{-1}\right)$ for one isolated $\mathrm{Gd}(\mathrm{III})$ ion $\left({ }^{8} \mathrm{~S}_{7 / 2}, \mathrm{~g}=2\right)$. Upon cooling, $\chi \mathrm{T}$ remains almost constant down to 100 $\mathrm{K}$ and then decreases and reaches a minimum value of $7.80 \mathrm{~cm}^{3} \mathrm{~K} \mathrm{~mol}^{-1}$ at $11 \mathrm{~K}$ (Inset in Figure 2a). The decreasing trend of $\chi \mathrm{T}$ upon cooling is due to the thermal depopulation of stark sublevels. ${ }^{55,56}$

$1 / \chi$ data at higher temperatures $(\mathrm{T}>150 \mathrm{~K})$ were fitted using Eq. 1 (Figure $2 \mathrm{~b}$ ) yields $\chi_{0} \approx$ $0.00285 \mathrm{~cm}^{3} / \mathrm{mol}, C \approx 13 \mathrm{~cm}^{3} \mathrm{~K}^{-1}$, and $\theta_{C W} \approx$ $-0.15 \mathrm{~K}$. The negligible value of $\theta_{C W}$ suggests that the interaction between the Gd spins is very weak. The experimental effective moment was calculated to be $\mu_{\text {eff }} \approx 7.96 \mu_{\mathrm{B}}$ at room temperature, which is in excellent agreement with the expected theoretical value of $\mu_{\text {eff }} \approx 7.94 \mu_{\mathrm{B}}$. Inset of Figure S7(b) (in Supplementary Information) shows the magnetization isotherm at $2.1 \mathrm{~K}$ measured up to $H=9 \mathrm{~T}$. Magnetization $(M)$ increases with increasing magnetic field $(H)$ and reaches the saturation with a value of $M_{\text {sat }} \approx 7.036 \mu_{\mathrm{B}}$ at $9 \mathrm{~T}$. The observed value of $M_{\text {sat }}$ agrees reasonably with the value $7 \mu_{\mathrm{B}}$ anticipated for an isolated $\mathrm{Gd}(\mathrm{III})$ ion with $S=7 / 2$, $L=0$ and $g=2.0$. The overall shape of the curve is similar to that expected for a paramagnet.

For Compound 3, $\chi(T)$ measured at $1 \mathrm{~T}$ is shown in Figure 3a. $\chi(T)$ data increases gradually as the temperature decreases in a Curie-Weiss $(\mathrm{CW})$ manner, reflecting the paramagnetic nature of the compound. No indication of any magnetic ordering was found down to $2 \mathrm{~K} . \chi T(T)$ value is equal to $11.63 \mathrm{~cm}^{3} \mathrm{~K} \mathrm{~mol}^{-1}$ at 350 $\mathrm{K}$, which is close to the value expected for one isolated $\mathrm{Tb}$ (III) ion (11.82 $\left.\mathrm{cm}^{3} \mathrm{~K} \mathrm{~mol}^{-1},{ }^{7} \mathrm{~F}_{6}, \mathrm{~J}=6, \mathrm{~g}=3 / 2\right)$.
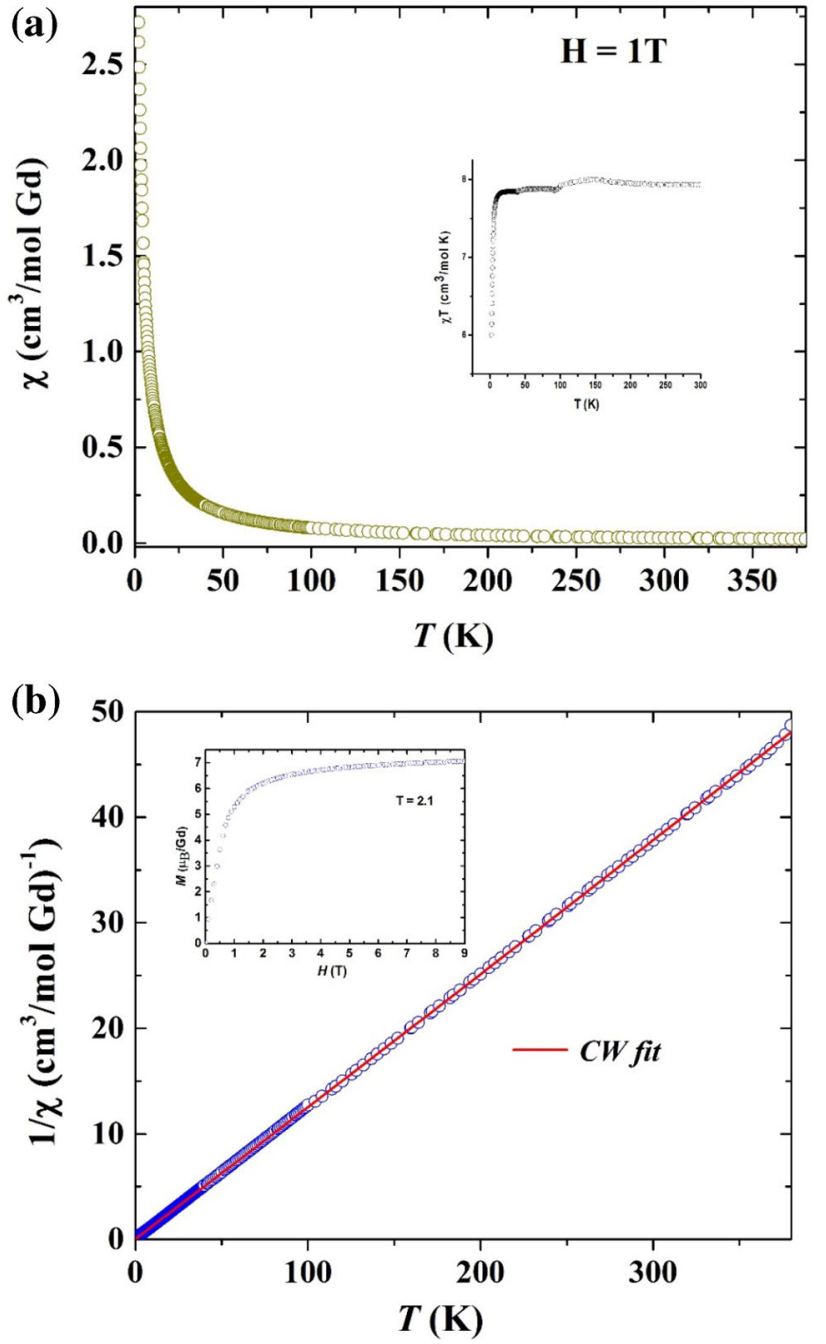

Figure 2. (a) $\chi$ vs $T$ of compound 2 measured at $H=1 \mathrm{~T}$. (b) $1 / \chi$ vs. $T$ and the solid line is the CW fit using Eq. 1 at high temperatures which is extrapolated down to $0 \mathrm{~K}$. Inset: Magnetization isotherm measured at $T=2.1 \mathrm{~K}$.

The CW fitting at high temperatures $(150 \mathrm{~K}-380 \mathrm{~K})$ yields $\chi_{0} \approx-0.001 \mathrm{~cm}^{3} / \mathrm{mol}, C \approx 11.94 \mathrm{~cm}^{3} \mathrm{~K}^{-1}$, and $\theta_{C W}-\approx 0.71 \mathrm{~K}$. At room temperature, the experimental effective moment was calculated to be $\mu_{\text {eff }} \approx$ $9.65 \mu_{\mathrm{B}}$. This value is closely matching with the expected theoretical value of $\mu_{\text {eff }} \approx 9.72 \mu_{\mathrm{B}}$. Inset of Figure $3 \mathrm{~b}$ shows the magnetization isotherm at $2.1 \mathrm{~K}$ measured up to $H=9$ T. $M$ increases with $H$ and saturates at around $3 \mathrm{~T}$.

For Compound 4, as shown in Figure $4 \mathrm{a}, \chi(\mathrm{T})$ data shows a CW behaviour, which is typical for a paramagnet. The CW fitting yields $\chi_{0} \approx-0.0017 \mathrm{~cm}^{3} / \mathrm{mol}$, $C \approx 12.73 \mathrm{~cm}^{3} \mathrm{~K}^{-1}$, and $\theta_{C W} \approx 0.01 \mathrm{~K}$. The $\chi T$ value is $12.56 \mathrm{~cm}^{3} \mathrm{~K} \mathrm{~mol}^{-1}$ at $350 \mathrm{~K}$. From the room temperature $\chi T$ value, the effective moment was calculated to be $\mu_{\text {eff }} \approx 10.03 \mu_{\mathrm{B}}$ which is comparable to the expected theoretical value of $\mu_{\mathrm{eff}} \approx 10.65 \mu_{\mathrm{B}}$ for Dy(III) ions 

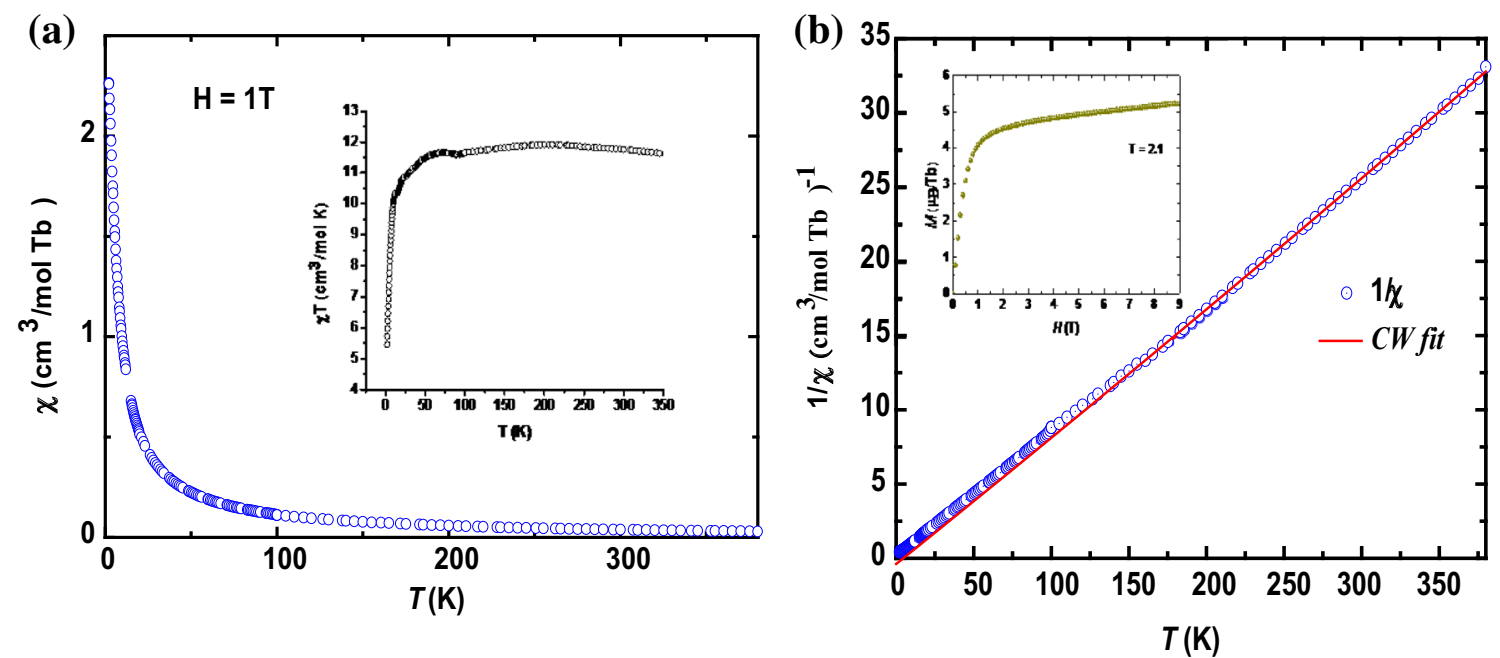

Figure 3. (a) $\chi$ vs $T$ of compound 3 measured at $H=1 \mathrm{~T}$. (b) $1 / \chi$ vs. $T$ and the solid line is the CW fit using Eq. 1 at high temperatures which is extrapolated down to $0 \mathrm{~K}$. Inset: Magnetization isotherm measured at $T=2.1 \mathrm{~K}$.
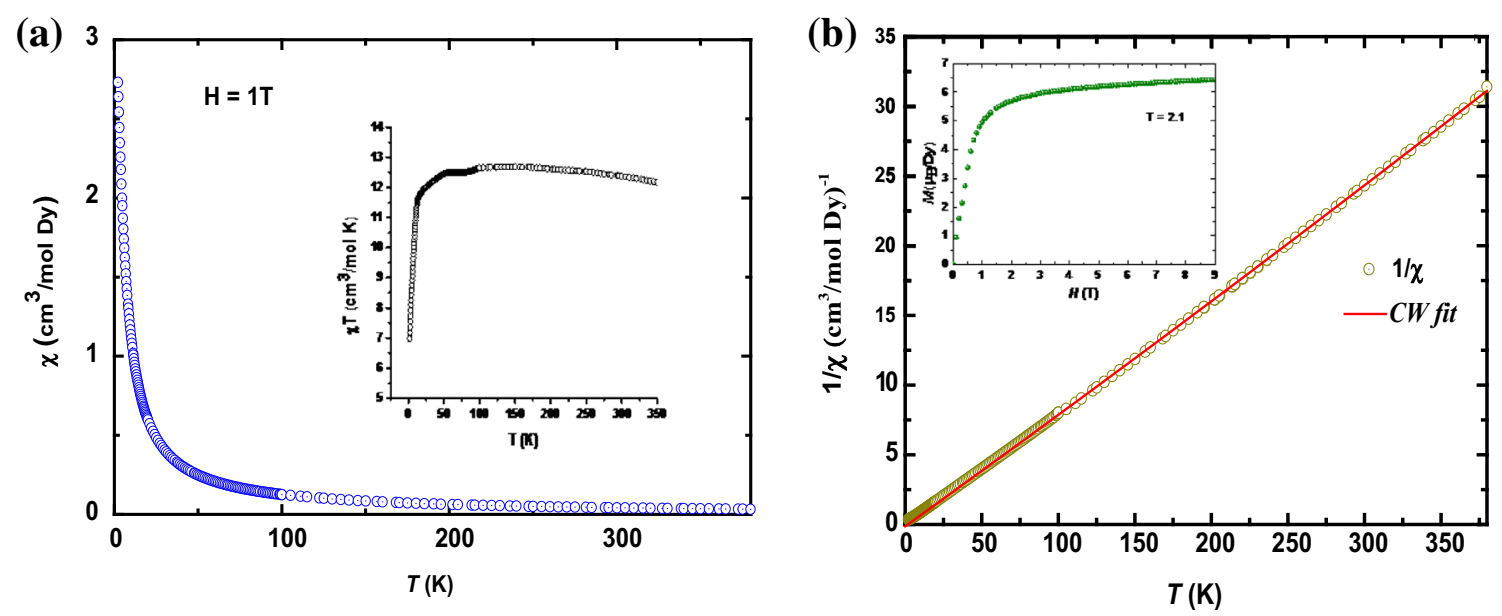

Figure 4. (a) $\chi$ vs $T$ of compound 4 measured at $H=1 \mathrm{~T}$. (b) $1 / \chi$ vs. $T$ and the solid line is the CW fit using Eq. 1 at high temperatures which is extrapolated down to $0 \mathrm{~K}$. Inset: Magnetization isotherm measured at $T=2.1 \mathrm{~K}$.

$\left(14.17 \mathrm{~cm}^{3} \mathrm{~K} \mathrm{~mol}^{-1},{ }^{6} \mathrm{H}_{15 / 2}, \mathrm{~J}=15 / 2, \mathrm{~g}=4 / 3\right)$. Inset of Figure $4 \mathrm{~b}$ shows the magnetization isotherm at 2.1 $\mathrm{K}$ measured up to $H=9 \mathrm{~T}$. $M$ increases with $H$ and saturates at around $3 \mathrm{~T}$.

\subsection{IR spectra and Thermal studies}

In the IR spectra, peaks at $1711 \mathrm{~cm}^{-1}, 1420-1585 \mathrm{~cm}^{-1}$, $1350 \mathrm{~cm}^{-1}$ due to stretching frequency of $\mathrm{C}=\mathrm{O}, \mathrm{C}$ $=\mathrm{C}, \mathrm{C}-\mathrm{N}$, respectively, were observed. The broad peak between $3200-3600 \mathrm{~cm}^{-1}$ is due to stretching frequency of $\mathrm{O}-\mathrm{H}$ from the hydrogen-bonded water molecules (Figure S2 in Supplementary Information). The TGA graphs show that the first weight loss starts at $120^{\circ} \mathrm{C}$ due to the loss of coordinated and lattice water molecules from the structures. Second weight loss up to $48-52 \%$ for the four compounds were observed due to the breakdown of the framework structure with the loss of chelidamic acid (Figure S3 in Supplementary Information). The calcined products were found to be poorly crystalline by PXRD and majority of the lines correspond to $\mathrm{La}_{2} \mathrm{O}_{3}$.

\subsection{Luminescence Properties}

The solid-state luminescence properties of compounds 1-4 as well as the free ligand CA were investigated at room temperature (Figure S7 in Supplementary Information). Free ligand CA displays a main emission band centered at $500 \mathrm{~nm}$ on excitation at $359 \mathrm{~nm}$. This 
emission peak may be attributed to the $\pi^{*} \rightarrow \pi$ or $\pi^{*} \rightarrow \mathrm{n}$ transition (reverse of the absorption bands) in the ligand. Emission bands at $543 \mathrm{~nm}$ and $555 \mathrm{~nm}$ for compounds 2 and 4, respectively, were observed. These emission bands are neither metal-to-ligand charge transfer (MLCT) nor ligand-to-metal charge transfer (LMCT) in nature and could be assigned to a combination of the charge transfer process and intra ligand emission because similar emissions are also observed for the free ligand.

In compounds $\mathbf{1}$ and $\mathbf{3}$, luminescence bands were observed on excitation at $359 \mathrm{~nm}$ and the characteristic emission from CA ligand around $500 \mathrm{~nm}$ almost disappeared (Figure S8 in Supplementary Information). New bands were observed and that could be due to $\mathrm{f}-\mathrm{f}$ electronic transition in $\mathrm{Ln}^{3+}$ ions. In compound $\mathbf{1}$ (Eu-CA), luminescence bands are due to various transitions that occur from the ${ }^{5} \mathrm{D}_{0}$ to ${ }^{7} \mathrm{~F}$ states. The intense peaks at 590, 615 and $694 \mathrm{~nm}$ result from the transitions ${ }^{5} \mathrm{D}_{0} \rightarrow{ }^{7} \mathrm{~F}_{1},{ }^{5} \mathrm{D}_{0} \rightarrow{ }^{7} \mathrm{~F}_{2}$ and, ${ }^{5} \mathrm{D}_{0} \rightarrow{ }^{7} \mathrm{~F}_{4}$, respectively. In compound 3 (Tb-CA), luminescence bands at 491, 545, 586 , and $621 \mathrm{~nm}$ are due to the transitions ${ }^{5} \mathrm{D}_{4} \rightarrow{ }^{7} \mathrm{~F}_{6}$, ${ }^{5} \mathrm{D}_{4} \rightarrow{ }^{7} \mathrm{~F}_{5}^{5} \mathrm{D}_{4} \rightarrow{ }^{7} \mathrm{~F}_{4}$ and ${ }^{5} \mathrm{D}_{4} \rightarrow{ }^{7} \mathrm{~F}_{3}$, respectively. The most intense emission corresponds to the hypersensitive transition of ${ }^{5} \mathrm{D}_{4} \rightarrow{ }^{7} \mathrm{~F}_{5}(545 \mathrm{~nm}$ ) (Figure $\mathrm{S} 8) .{ }^{57-59}$

\section{Conclusions}

A series of lanthanide(III) based coordination polymers using chelidamic acid (CA) were synthesized by solvothermal methods. The lanthanide ion adopts distorted dodecahedron geometry and linked with chelidamic acid to form two-dimensional layered structure. These layers are H-bonded to form the threedimensional supramolecular structure. From a structural point of view, it was shown that metal nodes are well isolated by ligand. As a result, the band gap of these materials depends solely on the organic ligand and HOMO-LUMO gap was not much changed with increasing number of the $f$-electrons. Due to weak bonding connectivity between the metal nodes and ligands the perturbation of the states related to the band gap are insignificant. Magnetic moments are influenced by the $f$-electrons and the observed values are closer to theoretical values. The present results suggest that optical and electronic properties are dependent on both the metal ion and ligand in these coordination polymers.

\section{Supplementary Information (SI)}

Crystallographic data for the structural analyses of compounds 1-4 have been deposited with the Cambridge Crystallographic Data Centre bearing the CCDC Nos. CCDC
1495104-1495107. These data can be available on request at free of charge from CCDC, Union Road, Cambridge, CB21EZ, UK (fax: +44-1223-336-033; e-mail: deposit@ccdc.ac.uk or http://www.ccdc.cam.ac.uk). TOPOS analysis, additional figures, PXRD, TGA, and IR spectra are available at www.ias.ac.in/chemsci.

\section{Acknowledgements}

We acknowledge financial support from Science and Engineering Research Board (SERB) and Department of Science and Technology (DST), Govt. of India.

\section{References}

1. Choppin G R 1989 Lanthanide Probes in Life, Chemical and Earth Sciences (New York: Elsevier)

2. Valeur B 2001 Molecular Fluorescence: Principles and Applications (New York: Wiley- VCH)

3. Reineke T M, Eddaoudi M, Fehr M, Kelley D and Yaghi O M 1999 From Condensed Lanthanide Coordination Solids to Microporous Frameworks Having Accessible Metal Sites J. Am. Chem. Soc. 1211651

4. Reineke T M, Eddaoudi M, O'Keefe M and Yaghi O M 1999 A Microporous Lanthanide-Organic Framework Angew. Chem. Int. Ed. 382590

5. Pan L, Huang $\mathrm{X} \mathrm{Y}, \mathrm{Li}$ J, Wu Y G and Zheng $\mathrm{N}$ 2000 Novel Single- and Double-Layer and ThreeDimensional Structures of Rare-Earth Metal Coordination Polymers: The Effect of Lanthanide Contraction and Acidity Control in Crystal Structure Formation Angew. Chem. Int. Edit. 39527

6. Benellim C and Gatteschi D 2002 Magnetism of lanthanides in molecular materials with transition-metal ions and organic radicals Chem. Rev. 1022369

7. Han Y F, Li X Y, Shen Z, Song Y, and You X Z 2010 Structures and properties of porous coordination polymers based on lanthanide carboxylate building units Inorg. Chem. 4910781

8. Baoming, Deng D, Junying $\mathrm{M}$, Chaowei $\mathrm{S}$ and Bin Z 2015 Two- and three-dimensional lanthanide-based coordination polymers assembled by the synergistic effect of various lanthanide radii and flexibility of a new binicotinate-containing ligand: in situ synthesis, structures, and properties RSC Adv. 52239

9. Lianchao L, Chaojun S, Fangfang D, Wenjing W and Daqiang Y 2016 Synthesis and characterization of Two Isostructural Lanthanide-Containing MetalOrganic Frameworks constructed from an Unprecedented $\left[\operatorname{Ln}_{7}\left(\mu_{3}-\mathrm{OH}\right)_{8}\right]^{13+}$ Cluster Chin. J. Chem. 34210

10. Binnemans K 2009 Lanthanide-based luminescent hybrid materials Chem. Rev. 1094283

11. Rocha J, Carlos L D, Paz F A and Ananiasa D 2011 Luminescent multifunctional lanthanides-based metalorganic frameworks Chem. Soc. Rev. 40926

12. Allendorf M D, Bauer C A, Bhakta R K and Houka R J T 2009 Luminescent metal-organic frameworks Chem. Soc. Rev. $\mathbf{3 8} 1330$

13. Jia J H, Lin X, Blake A J, Champness N R, Hubberstey P, Shao L M and Walker G 2006 Triggered Ligand 
Release Coupled to Framework Rearrangement: Generating Crystalline Porous Coordination Materials Inorg. Chem. 458838

14. Chandler B D, Yu J O, Cramb D T and Shimizu G K H 2007 Series of Lanthanide-Alkali Metal-Organic Frameworks Exhibiting Luminescence and Permanent Microporosity Chem. Mater. 194467

15. Mihalcea I, Zill N, Mereacre V, Anson C E and Powell A K 2014 Spontaneous resolution in homochiral helical [Ln (nic) 2 (Hnic)(NO3)] coordination polymers constructed from a rigid non-chiral organic ligand Cryst. Growth Des. 144729

16. Koeller S, Bernardinelli G, Bocquet B and Piguet C 2003 A Novel Extended Covalent Tripod for Assembling Nine-Coordinate Lanthanide(III) Podates: A Delicate Balance between Flexibility and Rigidity Chem. Eur. J. 9 1062

17. Kepert D 1982 Inorganic Stereochemistry (Berlin: Springer) Ch. $2 \& 12$

18. Xu N, Shi W, Liao D Z, Yan S P and Cheng P 2008 Template synthesis of lanthanide ( $\mathrm{Pr}, \mathrm{Nd}, \mathrm{Gd}$ ) coordination polymers with 2-hydroxynicotinic acid exhibiting ferro/antiferromagnetic interaction Inorg. Chem. 478748

19. Fang M, Chang L, Liu X, Zhao B, Zuo Y and Chen Z 2009 Fabrication and Properties of Eight Novel Lanthanide- Organic Frameworks Based on 4-Hydroxypyran-2, 6-dicarboxylate and 4Hydroxypyridine-2, 6-dicarboxylate Cryst. Growth Des. 94006

20. Mirzaei M, Hosseini H E, Lotfian N, Salimi A, Bauza A, Deun R V, Decadt R and Frontera A 2014 Syntheses, structures, properties and DFT study of hybrid inorganic-organic architectures constructed from trinuclear lanthanide frameworks and Keggin-type polyoxometalates Dalton Trans. 431906

21. Zou J P, Chen M H, Zhang L Z, Xing Q J and Xiong Z Q 2011 Syntheses, Structures and Optical Properties of a Series of Lanthanide Complexes with Chelidamic Acid and 4, 4'-Bipyridyl J. Chem. Crystallogr. 41820

22. Zou J P, Luo S L, Li M J, Tang X H, Xing Q J, Peng Q and Guo G C 2010 Syntheses, crystal structures, and magnetic and luminescent properties of a series of lanthanide coordination polymers with chelidamic acid ligand Polyhedron 292674

23. Guo X, Zhu G, Li Z, Sun F, Yang Z and Qiu S 2006 A lanthanide metal-organic framework with high thermal stability and available Lewis-acid metal sites Chem. Commun. 303172

24. Qiu Y, Deng H, Yang S, Mou J, Daiguebonne C, Kerbellec N, Guillou O and Batten S R 2009 Syntheses, crystal structures, and gas storage studies in new three-dimensional 5-aminoisophthalate praseodymium polymeric complexes Inorg. Chem. 483976

25. Guo X, Zhu G, Sun F, Li Z, Zhao X, Li X, Wang $\mathrm{H}$ and Qiu S 2006 Synthesis, structure, and luminescent properties of microporous lanthanide metal- organic frameworks with inorganic rod-shaped building units Inorg. Chem. $\mathbf{4 5} 2581$

26. Wu J Y, Yeh T T, Wen Y S, Twu J and Lu K L 2006 Unusual Robust Luminescent Porous Frameworks SelfAssembled from Lanthanide Ions and 2, 2 '-Bipyridine4, 4 '-dicarboxylate Cryst. Growth Des. 6467
27. Bunzli J C G and Piguet C 2002 Lanthanide-containing molecular and supramolecular polymetallic functional assemblies Chem. Rev. 1021897

28. Zhao X, Wang D X, Chen Q, Chen J B, Lin G Y, Yue S T and Cai Y P 2012 Effect of lanthanide contraction on structures of lanthanide coordination polymers based on 5-aminoisophthalic acid and oxalate Inorg. Chem. Commun. 2312496

29. Xiang S C, Hu S M, Sheng T L, Chen J S and Wu X T 2009 Structural diversity of infinite $3 \mathrm{~d}-4 \mathrm{f}$ heterometallic cluster compounds driven by various lanthanide radii Chem. Eur. J. 1512496

30. He Z, Gao E Q, Wang Z M, Yan C H and Kurmoo M 2005 Coordination Polymers Based on Inorganic Lanthanide(III) Sulfate Skeletons and an Organic Isonicotinate $N$-oxide Connector: Segregation into Three Structural Types by the Lanthanide Contraction Effect Inorg. Chem. 44862

31. Liu C M, Xiong M, Zhang D Q, Du M and Zhu D B 2009 Two-and three-dimensional lanthanide-organic frameworks constructed using 1-hydro-6-oxopyridine3-carboxylate and oxalate ligands Dalton Trans. 29 5666

32. Lin J, Chai P, Diefenbach K, Shatruk M and AlbrechtSchmitt T E 2014 Challenges in the Search for Magnetic Coupling in 3d/4f Materials: Syntheses, Structures, and Magnetic Properties of the Lanthanide Copper Heterobimetallic Compounds, $\mathrm{RE}_{2} \mathrm{Cu}\left(\mathrm{TeO}_{3}\right)_{2}\left(\mathrm{SO}_{4}\right)_{2}$ Chem. Mater. 262187

33. Lin J, Diefenbach K, Kikugawa N, Baumbach R E and Albrecht- Schmitt T E 2014 Dimensional and coordination number reductions in a large family of lanthanide tellurite sulfates Inorg. Chem. $\mathbf{5 3} 8555$

34. Liu M S, Yu Q Y, Cai Y P, Su C Y, Lin X M, Zhou X $\mathrm{X}$ and Cai J W 2008 One-, two-, and three-dimensional lanthanide complexes constructed from pyridine-2, 6dicarboxylic acid and oxalic acid ligands Cryst. Growth Des. 84083

35. Wang Y W, Zhang Y L, Dou W, Zhang A J, Qin W W and Liu W S 2010 Synthesis, radii dependent self-assembly crystal structures and luminescent properties of rare earth (III) complexes with a tripodal salicylic derivative Dalton Trans. 399013

36. Lu W G, Jiang L and Lu T B 2010 Lanthanide contraction and temperature-dependent structures of lanthanide coordination polymers with imidazole-4, 5dicarboxylate and oxalate Cryst. Growth Des. 10 4310

37. Fessmann T and Kilburn J D 1999 Identification of Sequence-Selective Receptors for Peptides with a Carboxylic Acid Terminus Angew. Chem. Int. Edit. 381993

38. Searcey M, MeClean S, Madden B, McGown A T and Wakelin L P G 1998 Syntheses, DNA-cleaving properties and cytotoxicity of intercalating chelidamic acid derivatives Anti-Cancer Drug Des. 13837

39. Zhao B, Gao H L, Chen X Y, Cheng P, Shi W, Liao D Z, Yan S P and Jiang Z H 2006 A Promising MgII-IonSelective Luminescent Probe: Structures and Properties of Dy-Mn Polymers with High Symmetry Chem. Eur. J. 12149

40. Zou J P, Zhou G W, Zhang X, Wang M S, Lu Y B, Zhou W W, Guo G C and Huang J S 2009 A novel 
heterometal-organic coordination polymer with chelidamic acid: nonlinear optical and magnetic properties CrystEngComm 11972

41. Gao H L, Zhao B, Zhao X Q, Song Y, Cheng P, Liao D Z and Yan S P 2008 Structures and Magnetic Properties of Ferromagnetic Coupling 2D Ln- M Heterometallic Coordination Polymers ( $\mathrm{Ln}=\mathrm{Ho}, \mathrm{Er} ; \mathrm{M}=\mathrm{Mn}, \mathrm{Zn}$ ) Inorg. Chem. 4711057

42. Gao H L, Yi L, Zhao B, Zhao X Q, Cheng P, Liao D Z and Yan S P 2006 Synthesis and Characterization of MetalOrganic Frameworks Based on 4-Hydroxypyridine-2, 6dicarboxylic Acid and Pyridine-2, 6-dicarboxylic Acid Ligands Inorg. Chem. 455980

43. Lv D Y, Gao Z Q and Gu J Z 2011 Poly [[triaqua (i3-4-oxidopyridine-2, 6-dicarboxylato) terbium (III)] monohydrate] Acta Cryst. E 67357

44. SMART V5.628, SAINT V6.45a XPREP, SHELXTL; Bruker AXS Inc.: Madison, WI, 2004.

45. Sheldrick G M 1994 Siemens Area Correction Absorption Correction Program (Göttingen: University of Göttingen)

46. Sheldrick G M 1997 SHELXL-97 Program for Crystal Structure Solution and Refinement (Göttingen: University of Göttingen)

47. Farrugia J L 1999 WinGX suite for small-molecule single-crystal crystallography J. App. Crystallogr. 32837

48. Kubelka P 1948 New contributions to the optics of intensely light-scattering materials. Part I J. Opt. Soc. Am. 38448

49. Kubelka P 1954 New Contributions to the Optics of Intensely Light-Scattering Materials. Part II: Nonhomogeneous Layers J. Opt. Soc. Am. 44327

50. Murphy A B 2006 Modified Kubelka-Munk model for calculation of the reflectance of coatings with opticallyrough surfaces J. Phys. D: Appl. Phys. 393571

51. Blatov A V and Proserpio D M 2009 Topological relations between three-periodic nets. II. Binodal nets Acta Crystallogr. A $\mathbf{A 6 5} 202$
52. Lin $\mathrm{C} \mathrm{K}$, Zhao D, Gao W Y, Yang Z, Ye J, Xu T, Ge Q, Ma S and Liu D J 2012 Tunability of band gaps in metal-organic frameworks Inorg. Chem. 51 9039

53. Hendon C H, Tiana D, Fontecave M, Sanchez C, D'arras L, Sassoye C, Rozes L, Mellot-Draznieks C and Walsh A 2013 Engineering the optical response of the titanium-MIL-125 metal-organic framework through ligand functionalization J. Am. Chem. Soc. 135 10942

54. Asha K S, Reber A C, Pedicini A F, Khanna S N and Mandal S 2015 The Effects of Alkaline-Earth Counterions on the Architectures, Band-Gap Energies, and Proton Transfer of Triazole-Based Coordination Polymers Eur. J. Inorg. Chem. 2085

55. Ming F, Xiuhua L, Ping C and Bin Z 2015 Ferromagnetic interactions and slow magnetic relaxation behaviors of two lanthanide coordination polymers bridged by 2,6-naphthalenedicarboxylate ligand J. Solid State Chem. 223138

56. Yawer M, Kariem M, Sood $\mathrm{P}$ and Sheikh $\mathrm{H}$ N 2016 Lanthanide-based entangled coordination polymers connected by thiophene-2,5-dicarboxylate: solvothermal syntheses, crystal structures, luminescence and magnetic properties CrystEngComm 18 3617

57. You L X, Wang S, Xiong G, Poelman D, Smet P F, Ren B, Tian Y W and Sun Y 2014 Synthesis, structure and properties of 2D lanthanide coordination polymers based on N-heterocyclic aryl polycarboxylate ligands Dalton Trans. 4317385

58. Mahata P, Ramya K V and Natarajan S 2008 Pillaring of $\mathrm{CdCl}_{2}$-like layers in lanthanide metal-organic frameworks: Synthesis, structure, and photophysical Properties Chem. Eur. J. 145839

59. Mahata P, Ramya K V and Natarajan S 2007 Synthesis, structure and optical properties of rare-earth benzene carboxylates Dalton Trans. 4017 